\title{
Pediatric Traumatic Dural Arteriovenous Fistula
}

\author{
Michael Vassilyadi, Naveen Mehrotra, Mohammed F. Shamji, Jean Michaud
}

\begin{abstract}
Background: Dural arteriovenous fistulas are uncommon lesions in children, with traumatic lesions suspected to arise from incomplete arterial injury in proximity to a vein or draining sinus. Management of symptomatic acquired lesions requires evaluation of patient presentation, neurological status, and pathoanatomic configuration, with special consideration required for surgery secondary to failed endovascular technique. Case Report: A 12-year-old male sustained a bicycle fall causing a right temporo-parietal skull fracture associated with non-surgical right epidural hematoma and left contre-coup parietal contusion. Six-weeks later, he complained of a right temporal bruit with subsequent cerebral angiography demonstrating a dural-based fistula between the right middle meningeal artery and a dural vein draining into the sigmoid sinus. Intervention: Endovascular treatment of this lesion with glue embolization and coiling was unsuccessful, with angiographic illustration of previously unobserved collateral vessels and coils occupying the sigmoid sinus. A right temporo-parietal craniectomy was required to excise the dural-based fistula, followed by dural defect repair with bovine pericardium and subsequent cranioplasty. Six years later the patient remains neurologically intact with no headaches or bruit. Conclusions: Dural arteriovenous fistula can uncommonly occur following traumatic injury in children. Partial injury to the middle mengineal artery may have established arterial communication with the draining vein that became ectatic and tortuous under high pressure. Failure of primary endovascular treatment may complicate secondary surgical intervention.
\end{abstract}

RÉSUMÉ: Fistule artérioveineuse durale d'origine traumatique chez l'enfant. Contexte : Les fistules artérioveineuses durales sont des lésions rares chez les enfants et on soupçonne que les fistules traumatiques résultent d'un traumatisme artériel à proximité d'une veine ou d'un sinus de drainage. La prise en charge du patient qui présente une lésion acquise symptomatique doit tenir compte de la symptomatologie, inclure une bonne évaluation clinique afin d'établir l'état neurologique et préciser la configuration anatomopathologique en portant attention à certains éléments importants si une chirurgie était requise suite à l'échec d'une intervention endovasculaire. Cas clinique : Un garçon de 12 ans a subi une fracture du crâne temporo-pariétale droite, avec hématome épidural droit ne requérant pas de chirurgie, et une contusion pariétale gauche par contrecoup lors d'une chute à bicyclette. Il s'est plaint six semaines plus tard d'un bruit temporal droit et une angiographie cérébrale a montré la présence d'une fistule durale entre l'artère méningée moyenne droite et une veine durale se drainant dans le sinus sigmoïde. Intervention : Le traitement endovasculaire de cette lésion par embolisation de colle et de spirales métalliques (coils) s'est soldé par un échec et l'angiographie a mis en évidence des vaisseaux collatéraux qui n'avaient pas été notés antérieurement et des coils dans le sinus sigmoïde. Nous avons dû procéder à une craniectomie temporo-pariétale droite pour exciser la fistule dure-mérienne, réparer la brèche dure-mérienne avec du péricarde bovin et procéder à une cranioplastie. Le patient ne présente pas de séquelles neurologiques, de céphalée ou de bruit 6 ans plus tard. Conclusions : Chez les enfants, les fistules artérioveineuses durales sont rares suite à un traumatisme. Une lésion partielle à l'artère méningée moyenne peut avoir provoqué une communication entre l'artère et la veine de drainage qui est devenue ectasique et tortueuse lorsque soumise à une pression élevée. L'échec du traitement endovasculaire peut compliquer une chirurgie subséquente.

Can. J. Neurol. Sci. 2009; 36: 751-756

Intracranial dural arteriovenous fistulas (AVFs) account for $10-15 \%$ of all intracranial arteriovenous lesions, ${ }^{1}$ and in the pediatric population these lesions are often multiple and more complex in configuration than in the adult population. ${ }^{2-4}$ The lesion consists of an abnormal direct connection between a meningeal artery and either a meningeal vein or dural sinus. High mortality is observed among pediatric patients, with presentation in congestive heart failure among neonates and neurological deterioration in older children reported as high as $67 \%$ and $38 \%$ for these two groups respectively. ${ }^{5}$ Kincaid and coworkers $^{2}$ describe a series of seven likely prenatally acquired lesions with a review of the surrounding literature describing evidence against true congenital anomaly to include no genetic abnormality or association with other vascular anomalies alongside a mature vascular configuration. ${ }^{6,7}$ They advocate for expeditious endovascular embolotherapy as the mainstay of therapy for life-saving result in the setting of cardiovascular failure and symptomatic improvement in neurological dysfunction. Indeed, these lesions also exhibit a more aggressive

From the Division of Neurosurgery (MV, NM), Children's Hospital of Eastern Ontario; Division of Neurosurgery (MV, MFS), Division of Anatomic Pathology and Laboratory Medicine (JM), The Ottawa Hospital, Ottawa, Canada.

Received April 7, 2009. Final Revisions Submitted June 3, 2009.

Correspondence to: Michael Vassilyadi, The Children's Hospital of Eastern Ontario, Division of Neurosurgery, 401 Smyth Road, Ottawa, Ontario, K1H 8L1, Canada. 

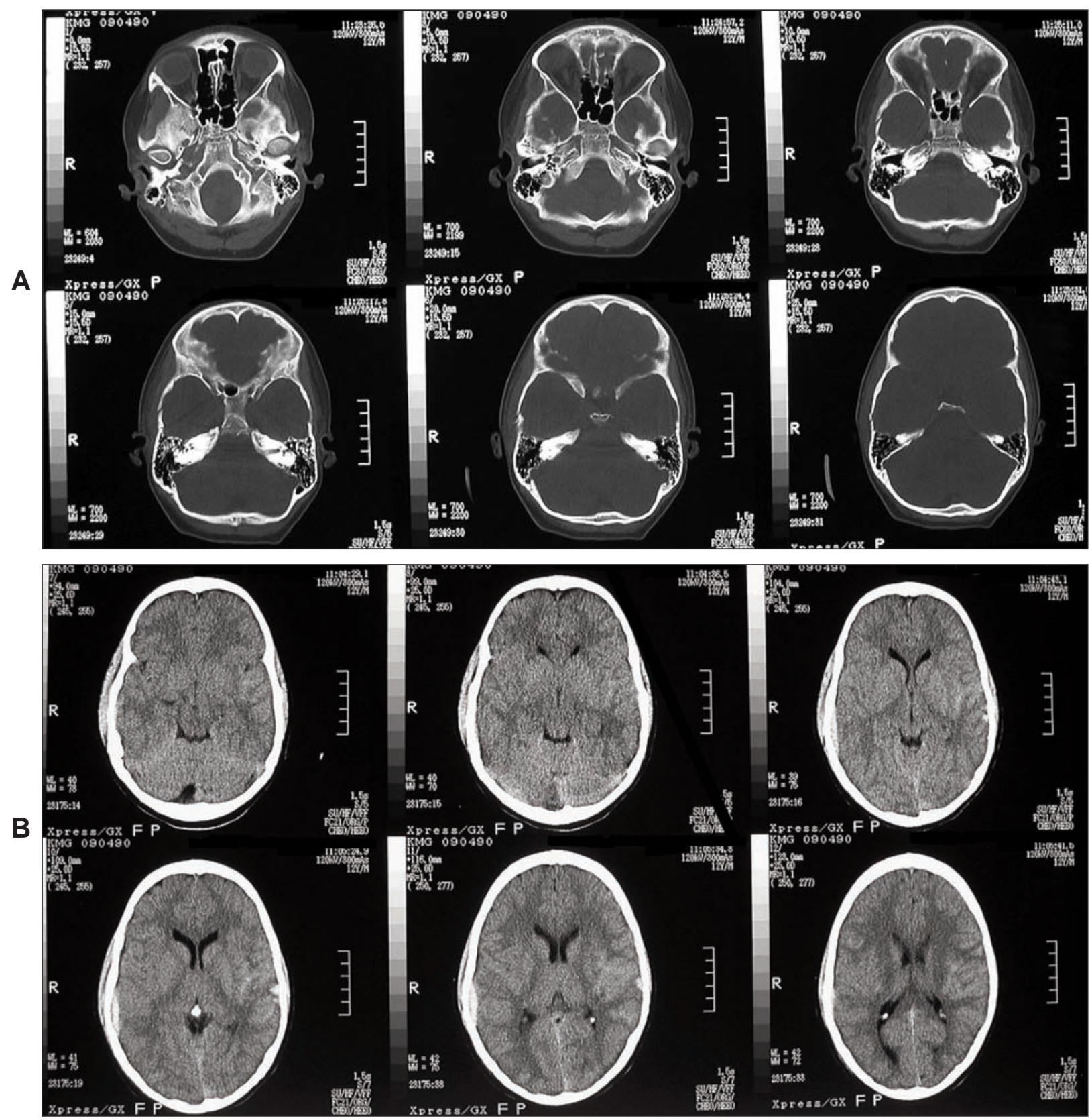

Figure 1: CT Head at the index head injury. (A) Non-depressed fracture of the right squamous temporo-parietal skull. (B) Underlying epidural hematoma associated with mild mass effect and no midline shift. Left contre-coup parietal lobe contusion and subarachnoid hemorrhage.

clinical course than in adults, ${ }^{3,4}$ although the natural history of traumatic acquired pediatric lesions is less well defined and may have a degree of indolence more characteristic of older individuals.

We present a case of a 12-year-old male who developed a benign acquired dural arteriovenous fistula following traumatic head injury. The patient was symptomatic from pulsatile tinnitus, failed endovascular therapy, and required surgical excision of the lesion to provide for adequate symptomatic relief.

\section{Case Report}

A 12-year-old male sustained a closed head injury by falling unhelmeted from a bicycle. Following a short staring spell that lasted two minutes, he began to speak coherently and had intact motor and sensory function. Upon presentation to the hospital, he complained of headaches, had thrice vomited, and was amnestic to the period surrounding the accident. Subgaleal swelling was observed in the right temporo-parietal region. Level of consciousness was maintained at Glasgow Coma Scale 


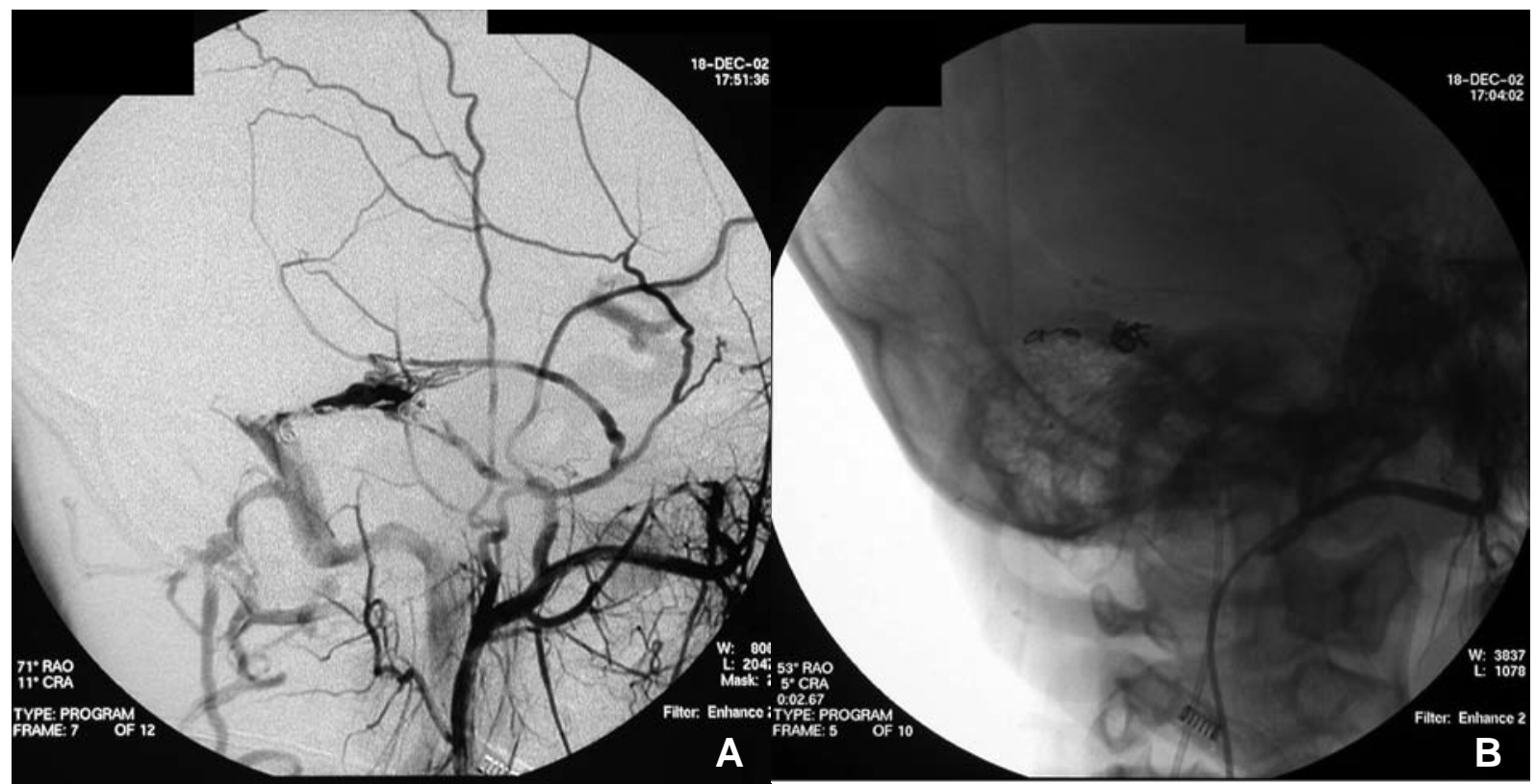

Figure 2: (A) Right external carotid angiogram revealed a dural arteriovenous fistula, supplied by a hypertrophied middle meningeal artery and two posterior branches and draining early through a dural vein into the sigmoid sinus. Through the larger of the two posterior branches, GDC and Vortx fibered coils were positioned through the fistula into the vein. Transvenously, Vortx fibered coils were deposited into the fistula, which displaced into the sigmoid sinus not allowing future microcatheter passage. (B) Scout view demonstrating position of coils.

of 15 in the emergency room and the neurological examination was normal.

Computed tomography of the head (Figure 1) revealed a nondepressed skull fracture in the squamous portion of the right temporal bone. This fracture was overlaid on an $8 \mathrm{~mm}$ epidural hematoma associated with mild mass effect and no midline shift. There was also a contre-coup left parietal contusion and traumatic subarachnoid hemorrhage. The patient was treated conservatively and discharged home three days following injury.

At six weeks, the patient complained of mild occipital headaches and pulsatile tinnitus that lasted for two weeks. This was most prominent on the right and in the bending position. Physical examination revealed a bruit immediately above the right ear. The remainder of the neurological examination was normal.

Magnetic resonance imaging revealed traces of hemosiderin in the right temporal and left parietal lobes. Magnetic resonance angiography showed a tangle of vessels in the right posterior temporal and inferior parietal region to originate from the external carotid artery. Magnetic resonance venography showed a small right transverse sinus, sigmoid sinus and internal jugular vein. Cerebral angiography demonstrated a large high-flow fistula from branches of the right middle meningeal artery emptying into a large vein that drained into a patent sigmoid sinus.

Endovascular treatment was attempted with selective transarterial placement of Gugliemi detachable coils (GDCs) (Boston Scientific) and Vortx fibered coils (Boston Scientific) into a feeding branch of the right middle meningeal artery (Figure 2). A second branch was infused with N-bucrylate and Lipiodol. These maneuvers resulted in reduced flow through the AVF. Supplemental transvenous catheterization was attempted with placement of Vortx fibered coils into the venous side of the fistula, although this was unsuccessful at reducing patency. Diagnostic cerebral angiography one month later showed persistence of the dural AVF with interval hypertrophy of the middle meningeal artery branches.

The dural AVF was successfully excised with the surrounding dura, through an elective right temporo-parietal craniectomy (Figure 3). The dura was circumferentially coagulated and transected peripheral to the bone flap, found to be adherent to the dura in the region of the AVF. Hemostasis was achieved from multiple arteries within the dura, but the venous outflow at the posterior and inferior margins was more difficult to coagulate because of the endovascular coils. Once the bone flap was lifted with the centrally adherent dura, there was no cortical component identified to the AVF. The brain was stained with hemosiderin, consistent with the patient's history of contusion. The dural defect was repaired with bovine pericardium (DuraGuard, Synovis) and a cranioplasty was performed using hydroxyapatite bone cement (Mimix, Walter Lorenz Surgical). The postoperative course was unremarkable, with resolution of the right pulsatile bruit. Symptoms have not recurred in six years follow-up. 


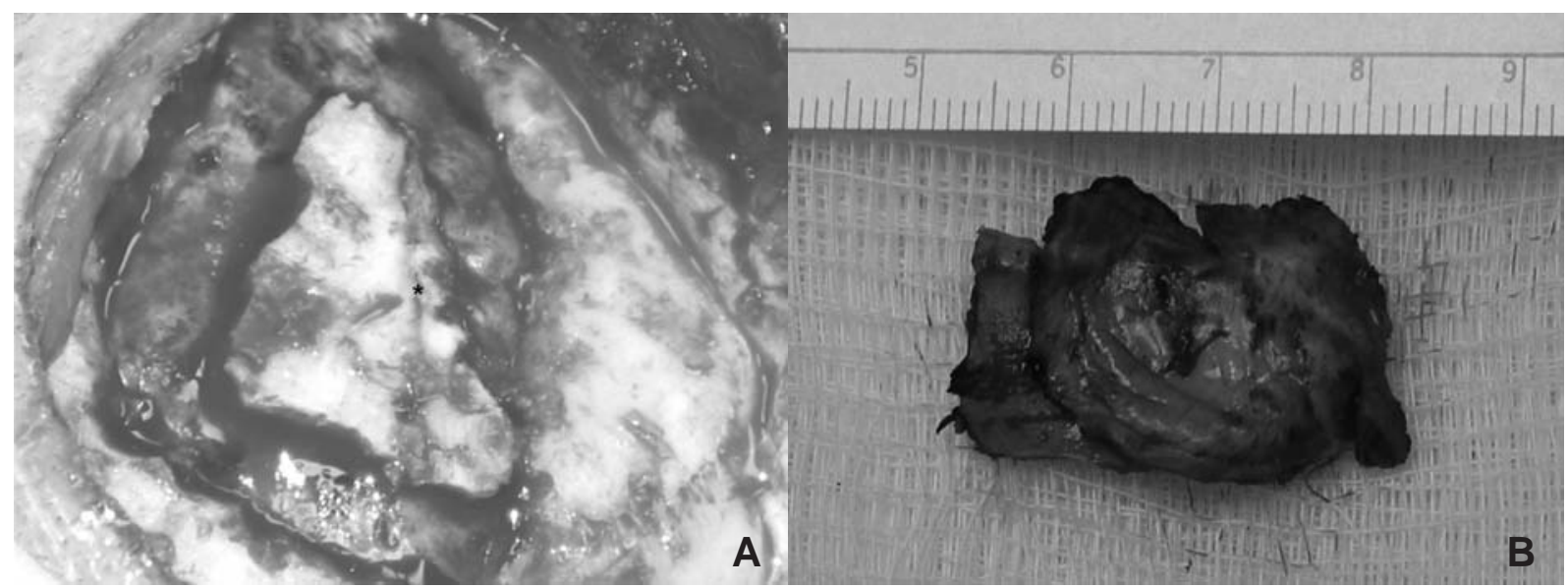

Figure 3: (A) Right temporal bone fracture (asterisk) after circumferential craniectomy and partial dural cauterization. Dural middle meningeal branches are exposed anterior, superior, and inferior to the craniectomy and contain the underlying adherent dural arteriovenous fistula. A dural vein leads to the sigmoid sinus, posteriorly and inferiorly situated relative to the craniectomized bone. (B) Specimen of the craniectomized bone and dura after circumferential bipolar cauterization and excision of the vascular dura. Endovascular coils protrude through inner dura.

\section{Pathology}

Pathological examination of the surgical specimen was consistent with an AVF undergoing partial obliteration after embolization with a granulomatous foreign body response. Firm fibrous tissue was observed on the inner surface of the excised rectangular bone flap (Figure 3). Histological evaluation revealed a gap in the bone occupied by non-inflammatory dense fibrous tissue and a blood vessel with mural chronic inflammatory changes (Figure 4). The adjacent dura mater had a cluster of blood vessels with elastin stain showing a very well defined internal elastic lamina illustrative of arteries. Other vascular structures revealed a mixture of appearance with larger arteries characterized by absent internal elastic lamina, and regions of focally thickened intima in which embolization material was occasionally absent or present. Elastin stain showed elastic lamina remnants in the embolized vascular structures, with iron stain showing dura mater to contain iron pigment. Recent hemorrhage was also observed alongside siderophages.

\section{Discussion}

Dural AVFs in pediatric patients have been classified by Lasjaunias and coworkers ${ }^{4}$ to include dural sinus malformations in neonates, infantile dural arteriovenous shunts in children, and adult type of dural arteriovenous fistulas which are less common but still occur in pediatric patients. The most common arterial sources are the middle meningeal artery and the occipital artery, with the most common draining sinus system being the transverse-sigmoid complex. Dural AVFs have been defined as benign or aggressive based on the direction of cortical venous flow, ${ }^{8}$ with reversal of flow being suggestive of a more aggressive phenotype with higher likelihood of intracranial hemorrhage and nonhemorrhagic neurological deficit. Patients with benign dural AVFs present based on location either asymptomatic or with pulsatile bruit, orbital congestion, cranial nerve palsy, or chronic headache. Patients with aggressive dural AVFs may also be asymptomatic or present with intracranial hemorrhage, nonhemorrhagic neurologic ischemic defecit, dementia, papilledema, or death. In more recent reports, the aggressive dural AVF group has been subdivided by symptomatology at presentation with symptomatic cortical

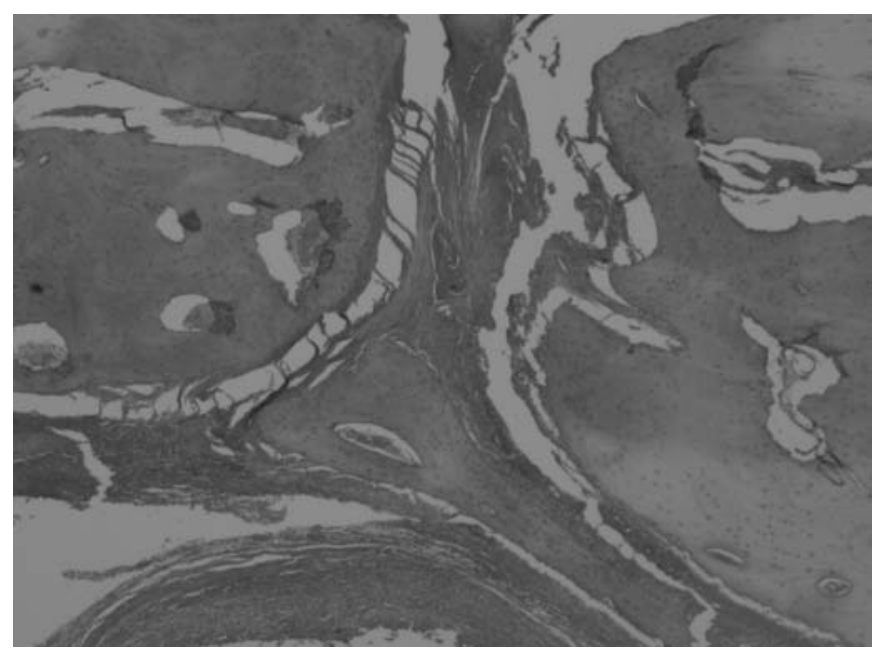

Figure 4: Low-power photomicrograph with hematoxylin-eosin stain demonstrating a fibrous gap in the bone at the previous fracture site. One adjacent vessel demonstrates chronic mural inflammation $(H+E$, $10 X$ magnification). 
venous drainage (CVD) portending a ten-fold higher event rate than asymptomatic counterparts. ${ }^{9}$ Other angiographic features suggestive of aggressive course with intracranial hemorrhage include aneurysmal dilatation of the draining vein or a venous varix. $^{8}$

Morita and coworkers report a series of 81 pediatric patients with dural AVFs, three of whom had involvement of posterior dural sinuses. ${ }^{5}$ Those lesions involving the posterior dural sinus were proposed to be more frequently acquired; and compared with adult lesions that have female preponderance, the neonatal and infantal onset lesions are more frequently reported to occur in males. The common modes of presentation included heart failure, hydrocephalus, macrocrania, dilated scalp veins, and cranial bruits; venous hypertension is rare with the involved sinus often forming a dilated sac, by way of contrast with adult patients in whom the sinus becomes stenosed or occluded in the adult variety. The presence of venous hypertension predisposes to hemorrhage, non hemorrhagic neurological deficit, and death, ${ }^{8}$ and is associated with reversal of flow in veins draining normal brain causing venous ischemia. ${ }^{10}$ The patient in this report presented with a benign dural AVF, symptomatic from an intolerable pulsatile tinnitus. This tinnitus may have resulted from the fistula proximity to the petrous temporal bone with its contained auditory apparatus.

Acquired dural AVFs in both adult and pediatric patients have been theorized to result from partial arterial injury following traumatic insult. Kitahara and coworkers ${ }^{11}$ describe the need for limited arterial damage and small volume of extravasated blood, although such conclusions are often skewed because patients with more extensive hemorrhage may be more likely to undergo surgical evacuation with secure control of the damaged artery. This patient presented with a head injury including an epidural hematoma with temporo-parietal fracture, with a mechanism likely to involve tearing of the middle mengineal artery parent or branch. Such vessels injured in close proximity to a meningeal vein or dural venous sinus can complete formation of a dural AVF. ${ }^{11,12}$ Conversely, the middle meningeal artery is anatomically accompanied by laterally situated paired veins, and sometimes these veins may form an intradural venous sinus with the middle meningeal artery situated within this sinus. Establishment of CVD transforms the dural AVF into a more aggressive lesion and may be initiated by development of venous sinus thrombosis. This promotes the growth of dural arteries and subsequent communication with the patent portion of the sinus. ${ }^{8,13}$ The dura mater has a rich network of arterial anastomoses accounting for why AVFs supplied solely by external meningeal branches can quickly recruit blood supply following embolization. ${ }^{13}$ Indeed, in this case, sequential angiography after attempted embolization revealed persistence of the dural AVF with newly-onset meningeal vessel hypertrophy and collateral vessel recruitment.

Common treatment modalities for dural AVFs include observation, endovascular intervention, surgery, and radiosurgery. Kincaid and coworkers ${ }^{2}$ report on seven cases of pediatric dural AVFs, all likely developing prenatally, of whom six were managed by endovascular therapy alone and one required secondary surgical intervention. The variety of agents available to embolize dural AVFs via transarterial route includes GDCs, fibered platinum microcoils, polyvinyl alcohol particles, and liquid adhesive agents. Onyx liquid embolic system is a nonadhesive agent with the advantage of longer setting time over which injection can be performed, providing the potential for arterio-arterial retrograde feeder filling and thus accomplishing multiple feeder embolization without the need for multiple catheterizations. ${ }^{14}$ Complications of transarterial embolization include ischemic cranial nerve palsies, transcollateral embolization of normal cerebral arteries, and systemic venous embolization. A transarterial approach may be unsuccessful when the lesion is fed by multiple arteries, though a transvenous approach may be more effective in these $\operatorname{cases}^{15}$ with the best indication for such treatment being when the involved sinus no longer contributes to drainage of normal brain parenchyma. ${ }^{16}$ Such technique provides for high rates of occlusion although it requires sacrifice of sinus flow with potential complications include alteration of AVF venous drainage to an aggressive lesion and potential of venous infarction or intracranial hemorrhage of normal cerebral tissue by outflow obstruction. ${ }^{17,18}$

Close observation may be selected because benign dural AVFs have low potential approximating $2 \%$ of developing CVD and becoming symptomatic and aggressive lesions. Conversely, early treatment is justified to prevent the development of this sequela, with other indications in patients with benign lesions including opthamological sequelae and intolerable bruits. ${ }^{8}$ Surgery may be offered based on failed endovascular therapy as a viable alternative to radiosurgery in order to achieve a rapid therapeutic effect, although careful assessment of the surgical risk must be made based on lesion location, patient medical and neurological status, and vascular configuration. ${ }^{19,20}$ Surgery provides effective treatment of dural AVFs, with craniotomy or craniectomy used to expose the lesion and enable direct obliteration. The optimal lesion for surgery should be an aggressive dural AVF that drains through a single cortical vein. Fistulas at the superior petrosal sinus and petrous ridge or in the anterior fossa related to the anterior inferior aspect of the falx are examples of surgical lesions where the AVF almost always drains into cortical veins through a single venous channel. Often, only obliteration of the draining vein is necessary to treat most of these lesions, although resection of the lesion when possible may be of value to protect against recurrence. ${ }^{21,22}$ Among adults having surgical management of dural AVFs, Kawaguchi and coworkers $^{23}$ describe that the presence of sinus occlusion with retrograde cortical vein flow supports that total lesion removal is possible, and the utilization of preoperative coil embolization did not affect the volume of procedural blood loss. Ushikoshi and coworkers $^{24}$ advise direct sinus packing for lesions draining directly into the dural sinus and for surgical interruption of draining veins when the lesions drain first into cortical veins. Surgery can also be considered with $\operatorname{staged}^{25,26}$ or intraoperative ${ }^{27}$ endovascular procedures.

Gamma knife radiosurgery has been used to treat dural AVFs when immediate devascularization is not required. ${ }^{28} \mathrm{~A}$ delay on the temporal order of years is required to achieve vascular occlusion, thereby minimizing the role of this modality as primary therapy for lesions with CVD. ${ }^{29}$ Radiosurgery has been used in the treatment of benign dural AVFs, particularly for patients with subjectively intolerable bruit, or for aggressive dural AVFs that are not amenable to endovascular treatment and surgery. ${ }^{30}$ More recently, stereotactic radiosurgery has been combined with transarterial embolization to treat low-risk dural 
AVFs, with embolization providing immediate symptom relief and radiosurgery engendering a higher likelihood of permanent fistula obliteration. ${ }^{31-33}$

In conclusion, dural AVFs are a rare lesion in the pediatric population and are most often acquired prenatally after maturation of the cardiovascular system. While the vascular configuration in the pediatric age group can be more complex than in acquired adult lesions, endovascular treatment remains the mainstay of therapy with success in both cardiovascular and neurological relief. The presented case was of a benign lesion with no cortical venous reflux and symptomatic from pulsatile tinnitus, but endovascular therapy failed to provide for lesion obliteration and surgical excision was ultimately required. The natural history and management of traumatic pediatric AVFs remains unclear and patients are best managed aggressively as in adults to prevent longstanding venous hypertension and irreversible brain injury.

\section{REFERENCES}

1. Cognard C, Gobin YP, Pierot L, Bailly AL, Houdart E, Casasco A, et al. Cerebral dural arteriovenous fistulas: clinical and angiographic correlation with a revised classification of venous drainage. Radiology. 1995 Mar;194(3):671-80.

2. Kincaid PK, Duckwiler GR, Gobin YP, Vinuela F. Dural arteriovenous fistula in children: endovascular treatment and outcomes in seven cases. AJNR Am J Neuroradiol. 2001 Jun-Jul; 22(6):1217-25.

3. Chaloupka JC. Endovascular therapy for dural arteriovenous fistulae. Seminars in Interventional Radiology. 1994;11:1-13.

4. Lasjaunias P, Magufis A, Goulao A, Suthipongchai S, Rodesch R, Alvarez H. Anatomoclinical aspects of dural arteriovenous shunts in children. Interventional Neuroradiology. 1996;2: 179-91.

5. Morita A, Meyer FB, Nichols DA, Patterson MC. Childhood dural arteriovenous fistulae of the posterior dural sinuses: three case reports and literature review. Neurosurgery. 1995 Dec;37(6): 1193-9; discussion 1199-200.

6. Garcia-Monaco R, Rodesch G, Terbrugge K, Burrows P, Lasjaunias P. Multifocal dural arteriovenous shunts in children. Childs Nerv Syst. 1991 Dec;7(8):425-31.

7. Roland J, Bernard C, Bracard S, Czorny A, Floquet J, Race JM, et al. Microvascularization of the intracranial dura mater. Surg Radiol Anat. 1987;9(1):43-9.

8. Satomi J, van Dijk JM, Terbrugge KG, Willinsky RA, Wallace MC. Benign cranial dural arteriovenous fistulas: outcome of conservative management based on the natural history of the lesion. J Neurosurg. 2002 Oct;97(4):767-70.

9. Strom RG, Botros JA, Refai D, Moran CJ, Cross DT, 3rd, Chicoine MR, et al. Cranial dural arteriovenous fistulae: asymptomatic cortical venous drainage portends less aggressive clinical course. Neurosurgery. 2009 Feb;64(2):241-7; discussion 247-8.

10. Davies MA, TerBrugge K, Willinsky R, Coyne T, Saleh J, Wallace $\mathrm{MC}$. The validity of classification for the clinical presentation of intracranial dural arteriovenous fistulas. J Neurosurg. 1996 Nov; 85(5):830-7.

11. Kitahara T, Shirai S, Owada T, Maki Y. Traumatic middle meningeal arteriovenous fistula. Report of 3 cases and analysis of 32 cases. Eur Neurol. 1977;16(1-6):136-43.

12. Wilson CB, Cronic F. Traumatic arteriovenous fistulas involving middle meningeal vessels. JAMA. 1964 Jun 15;188:953-7.

13. Borden JA, Wu JK, Shucart WA. A proposed classification for spinal and cranial dural arteriovenous fistulous malformations and implications for treatment. J Neurosurg. 1995 Feb;82(2): 166-79.

14. Cognard C, Januel AC, Silva NA Jr, Tall P. Endovascular treatment of intracranial dural arteriovenous fistulas with cortical venous drainage: new management using Onyx. AJNR Am J Neuroradiol. 2008 Feb;29(2):235-41.
15. Houdart E, Saint-Maurice JP, Chapot R, Ditchfield A, Blanquet A, Lot $\mathrm{G}$, et al. Transcranial approach for venous embolization of dural arteriovenous fistulas. J Neurosurg. 2002 Aug;97(2):280-6.

16. Roy D, Raymond J. The role of transvenous embolization in the treatment of intracranial dural arteriovenous fistulas. Neurosurgery. 1997 Jun;40(6):1133-41; discussion 1141-4.

17. Klisch J, Huppertz HJ, Spetzger U, Hetzel A, Seeger W, Schumacher M. Transvenous treatment of carotid cavernous and dural arteriovenous fistulae: results for 31 patients and review of the literature. Neurosurgery. 2003 Oct;53(4):836-56; discussion 856-7.

18. Oishi H, Arai H, Sato K, Iizuka Y. Complications associated with transvenous embolisation of cavernous dural arteriovenous fistula. Acta Neurochir (Wien). 1999;141(12):1265-71.

19. Bavinzski G, Richling B, Killer M, Gruber A, Levy D. Evolution of different therapeutic strategies in the treatment of cranial dural arteriovenous fistulas--report of 30 cases. Acta Neurochir (Wien). 1996;138(2):132-8.

20. Barnwell SL, Halbach VV, Higashida RT, Hieshima G, Wilson CB. Complex dural arteriovenous fistulas. Results of combined endovascular and neurosurgical treatment in 16 patients. J Neurosurg. 1989 Sep;71(3):352-8.

21. Lawton MT, Chun J, Wilson CB, Halbach VV. Ethmoidal dural arteriovenous fistulae: an assessment of surgical and endovascular management. Neurosurgery. 1999 Oct;45(4):80510; discussion 810-11.

22. Halbach VV, Higashida RT, Hieshima GB, Wilson CB, Barnwell SL, Dowd CF. Dural arteriovenous fistulas supplied by ethmoidal arteries. Neurosurgery. 1990 May;26(5):816-23.

23. Kawaguchi T, Hosoda K, Shibata Y, Kidoguchi K, Koyama J, Tamaki N. Direct surgical removal of the dural arteriovenous fistula involving the transverse-sigmoid sinuses. J Clin Neurosci. 2002;9(S1):16-18

24. Ushikoshi S, Houkin K, Kuroda S, Asano T, Iwasaki Y, Miyasaka $\mathrm{K}$, et al. Surgical treatment of intracranial dural arteriovenous fistulas. Surg Neurol. 2002 Apr;57(4):253-61.

25. Goto K, Sidipratomo P, Ogata N, Inoue T, Matsuno H. Combining endovascular and neurosurgical treatments of high-risk dural arteriovenous fistulas in the lateral sinus and the confluence of the sinuses. J Neurosurg. 1999 Feb;90(2):289-99.

26. Kakarla UK, Deshmukh VR, Zabramski JM, Albuquerque FC, McDougall CG, Spetzler RF. Surgical treatment of high-risk intracranial dural arteriovenous fistulae: clinical outcomes and avoidance of complications. Neurosurgery. 2007 Sep;61(3):44757; discussion 457-9.

27. Kong DS, Kwon KH, Kim JS, Hong SC, Jeon P. Combined surgical approach with intraoperative endovascular embolization for inaccessible dural arteriovenous fistulas. Surg Neurol. 2007 Jul; 68(1):72-7; discussion 78 .

28. Pan HC, Sheehan J, Huang CF, Yang DY. Two consecutive dural arteriovenous fistulae in a child: a case report of successful treatment with gamma knife radiosurgery. Childs Nerv Syst. 2007 Oct;23(10):1185-90.

29. van Dijk JM, terBrugge KG, Willinsky RA, Wallace MC. Clinical course of cranial dural arteriovenous fistulas with long-term persistent cortical venous reflux. Stroke. 2002 May;33(5): 1233-6.

30. Soderman M, Edner G, Ericson K, Karlsson B, Rahn T, Ulfarsson E, et al. Gamma knife surgery for dural arteriovenous shunts: 25 years of experience. J Neurosurg. 2006 Jun;104(6):867-75.

31. Friedman JA, Pollock BE, Nichols DA, Gorman DA, Foote RL, Stafford SL. Results of combined stereotactic radiosurgery and transarterial embolization for dural arteriovenous fistulas of the transverse and sigmoid sinuses. J Neurosurg. 2001 Jun;94(6): 886-91.

32. Link MJ, Coffey RJ, Nichols DA, Gorman DA. The role of radiosurgery and particulate embolization in the treatment of dural arteriovenous fistulas. J Neurosurg. 1996 May;84(5): 804-9.

33. Heros RC. Gamma knife surgery for dural arteriovenous fistulas. J Neurosurg. 2006 Jun;104(6):861-3; discussion 865-6. 